erythrocyte recovery; $82 \%$ and $24.3 \%$ for platelets and leukocytes, respectively; $97.8 \%$ for heparin).

Cell-derived microparticles are, on average, smaller in diameter than platelets and range in size from about $100 \mathrm{~nm}$ to $1.0 \mu \mathrm{m}$. Thus, the largest microparticles may overlap in size with platelets, which on average range in from $1.0 \mu \mathrm{m}$ to $5.0 \mu \mathrm{m}$. Both erythrocyte-derived microparticles and platelet-derived microparticles were removed efficiently (97\% and 99\%; $P=0.002$ and $P<.001$, respectively). Interestingly, the efficiency of the Cell Saver device to remove platelet-derived microparticles as well as erythrocyte-derived microparticles was significantly increased compared with the efficiency to remove thrombocytes $(P=.019$ and $P=.002$, respectively; Wilcoxon signed rank test). Thus, cell-derived vesicles, which on average are smaller in diameter than thrombocytes, are removed more efficiently from blood by a Cell Saver device than thrombocytes in a clinical setting.

This study is the first to directly evaluate the efficiency of a Cell Saver device to remove cell-derived microparticles from patient blood. Our data show that a Cell Saver device efficiently reduces the numbers of coagulation- and inflammation-promoting microparticles. From these data we cannot exclude that microparticles may bind to cells present within the blood or that low numbers of microparticles are generated by cell activation during the passage of blood through the Cell Saver device.

\section{References}

1. Nieuwland R, Berckmans RJ, Rotteveel-Eijkman RC, Maquelin KN, Roozendaal KJ, Jansen PG, et al. Cell-derived microparticles generated in patients during cardiopulmonary bypass are highly procoagulant. Circulation. 1997;96:3534-41.

2. van Putten J, van de Ruit M, Beunis M, Hemker HC. Automated determination of heparin with chromogenic substrates. Haemostasis. 1984;14:184-94.

3. Berckmans RJ, Nieuwland R, Boing AN, Romijn FP, Hack CE, Sturk A. Cell-derived microparticles circulate in healthy humans and support low grade thrombin generation. Thromb Haemost. 2001;85:639-46.

\title{
Primary intrapulmonary thymoma associated with congenital hyperhomocysteinemia
}

\author{
Alessando Stefani, MD, ${ }^{a}$ Edouard Boulenger, MD, ${ }^{\mathrm{b}}$ Sylvie Mehaut, MD, ${ }^{\mathrm{c}}$ Adrian Ciupea, $\mathrm{MD},{ }^{\mathrm{c}}$ and Marco Alifano, MD, \\ Paris and Troyes, France
}

$\mathrm{P}$ rimary intrapulmonary thymomas (PITs) are very uncommon, with 28 cases reported to date. ${ }^{1-3}$ Because of the paucity of studies, the biologic behavior and pathologic features of these neoplasms are not well known. The C677T methylenetetrahydrofolate reductase (MTHFR) genotype is a congenital disorder leading to low folate levels; the resultant mild hyperhomocysteinemia is associated with increased risk of venous thromboembolism and malignancies. ${ }^{4,5}$

We present a case of PIT associated with hyperhomocysteinemia caused by the $\mathrm{C} 677 \mathrm{~T}$ variant of MTHFR.

\section{Clinical Summary}

A 73-year-old woman was admitted for acute dyspnea with bronchospasm in a chronic obstructive pulmonary disease pathologic

From the Department of Thoracic Surgery, ${ }^{\text {a }}$ Hôtel-Dieu University Hospital, Paris, France; and the Departments of Thoracic Surgery ${ }^{\mathrm{b}}$ and Pathology, ${ }^{\mathrm{c}}$ Hospital of Troyes, Troyes, France.

Received for publication Feb 24, 2007; accepted for publication March 29, 2007.

Address for reprints: Alessandro Stefani, MD, Department of Thoracic Surgery, Hôtel Dieu University Hospital, 1, Place du Parvis Notre Dame, 75001, Paris, France (E-mail: stefani.alessandro@unimore.it).

J Thorac Cardiovasc Surg 2007;134:799-801

$0022-5223 / \$ 32.00$

Copyright $\odot 2007$ by The American Association for Thoracic Surgery doi:10.1016/j.jtcvs.2007.03.052 substrate. Her medical history was marked by episodes of venous thrombosis caused by a mutation of the MTHFR gene that imposed a preventive anticoagulant therapy. Chest radiography revealed an 18-mm nodule in the right upper lobe, which was confirmed by a computed tomographic scan (Figure 1). A positron emission tomographic scan showed a moderate uptake in correspondence of the lesion (standardized uptake value, 2.2). The results of bronchoscopy and computed tomographic scanning of the brain were normal.

A primary pulmonary tumor was suspected. Thoracotomy was performed by one of us (E.B.), and a nodule was found in the right upper lobe close to the hilum. Frozen examination revealed cells of uncommon feature suspected for malignancy. A right upper lobectomy with full nodal dissection was performed.

Macroscopic examination showed a well-circumscribed and encapsulated nodule (Figure 2, a). Histologic evaluation revealed the presence of 2 cell populations: epithelioid and lymphocytic (Figure 2,b). The epithelioid component was predominant and admixed with scattered lymphocytes. No areas of necrosis and very few mitoses could be identified. Immunohistochemical analysis demonstrated strong staining for cytokeratin 5 and 6 and epithelial membrane antigen in the epithelioid component, with negative staining for cytokeratin 7 , thyroid transcription factor 1 , and calretinine. These histologic findings were consistent with mixed or type $\mathrm{AB}$ thymoma. All lymph nodes were free of tumor.

The postoperative course was uneventful, and the patient is free of recurrence 2 years after the operation. 


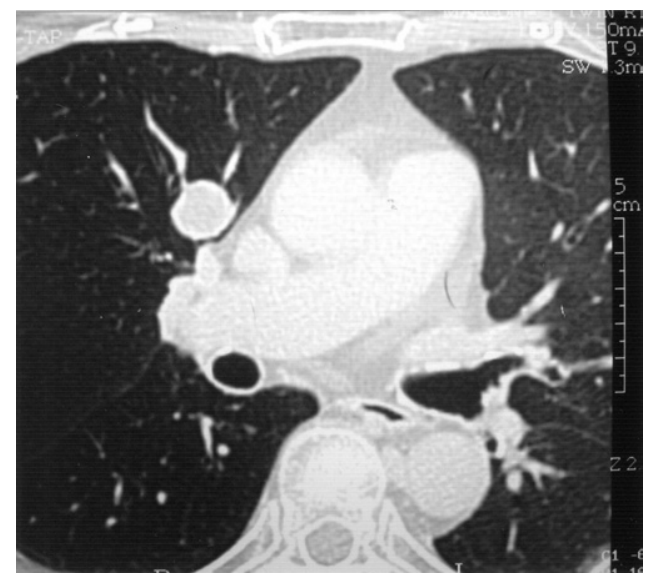

Figure 1. Chest computed tomographic scan showing a nodule in the anterior segment of the right upper lobe. The lesion appeared well-circumscribed and heterogeneous (42 and 106 Hounsfield units in the superior and inferior part, respectively).

\section{Discussion}

To our knowledge, 29 cases of PIT have been described, including this one. ${ }^{1-3}$ Pathogenesis is still a subject of debate: the most supported theory is that these tumors derive from ectopic thymic tissue, resulting from an embryologic displacement, but a teratomatous origin has also been invoked. ${ }^{1}$

The number of tumors reported is too small to clearly predict their biologic behavior. PITs occurred usually from the sixth decade of life, ${ }^{1-3}$ and a slight female predominance has been found. ${ }^{3}$ The right side was more often affected, ${ }^{1}$ with no preference in hilar or peripheral location. ${ }^{2}$ Patients were more commonly asymptomatic. $^{3}$

The histologic spectrum of these lesions ranges from lymphocyterich to predominantly epithelioid to spindle-cell thymoma. ${ }^{1}$ In most cases tumors appeared as well-circumscribed lesions, with low mitotic activity and minimal atypia. PIT might represent a serious diagnostic challenge for the pathologist; the differential diagnosis includes lymphoma and primary or metastatic carcinoma of the lung. Immunohistochemical stains might be of aid, but morphologic features are of basic importance. ${ }^{1}$

Most reported cases of PIT were slow-growing tumors with a good prognosis when surgically resected. ${ }^{1-3}$ Because preoperative diagnosis, either on biopsy specimens or frozen sections, is very difficult, PITs are usually diagnosed postoperatively. Therefore indications about the surgical management are difficult to define and to apply (eg, type of resection or need for mediastinal dissection).

Our case was classified as a type AB thymoma, an essentially nonaggressive lesion; it confirms the low grade of malignancy of PIT and its favorable outcome if completely resected.

The association between PITs and myasthenia gravis is less frequent than for mediastinal thymomas. As far as we know, 3 patients with PIT had symptoms of myasthenia gravis, whereas other syndromes associated with mediastinal thymomas have never been described for PITs.
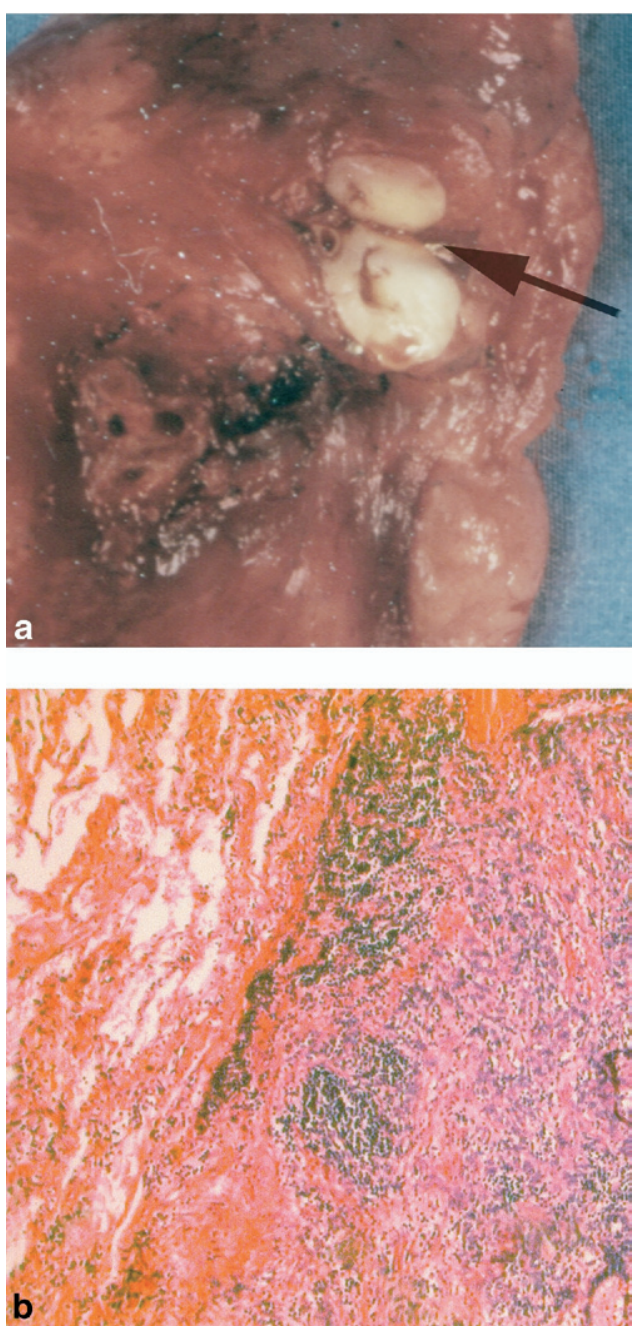

Figure 2. The photograph (a) shows a whitish, well-encapsulated tumor (black arrow) within the parenchyma of the right upper lobe. The microphotograph (b) show a peripheral type AB mixed area (right) close to the lung parenchyma (left) with an epithelioid population composed of large, round- to oval-shaped epithelial cells alternating with areas showing a spindle-cell morphology, separated by thin connective tissue strands, and accompanied by a sprinkling of mature small lymphocytes (hematoxylin and eosin stain).

The C677T variant of the MTHFR gene is an inherited congenital disorder altering the metabolism of folic acid. ${ }^{4}$ The resulting low folate levels influence the homocysteine remethylation pathway, and this results in mild hyperhomocysteinemia. Increased levels of homocysteine have been related to an increased risk of venous thromboembolism, pregnancy loss, anomalous progeny, cancer (eg, hematologic malignancies), and brain and colon tumors. ${ }^{4,5}$ Our patient had the heterozygous variant of the C677T MTHFR genotype, which induces intermittent moderate hyperhomocysteinemia and leads to recurrent venous thromboses. Although the vascular toxicity of hyperhomocysteinemia is well demonstrated, the association between 
altered levels of this thiol and cancer is a recent acquisition, and its clinical significance has yet to be defined. This is the first article reporting an association between MTHFR variant/hyperhomocysteinemia and thymoma, supporting the role of hyperhomocysteinemia as a risk factor for cancer.

\section{References}

1. Moran CA, Suster S, Fishback NF, Koss MN. Primary intrapulmonary thymoma. A clinicopathologic and immunihistochemical study of eight cases. Am J Surg Pathol. 1995;19:304-12.
2. Ishibashi H, Takahashi S, Hosaka T, Shibuya J, Suzuki S, Handa M. Primary intrapulmonary thymoma successfully resected with vascular reconstruction. Ann Thorac Surg. 2003;76:1735-7.

3. Srivastava A, Padilla O, Alroy J, Ucci A, Pilichowska M, Dalcy B, et al. Primary intrapulmonary spindle-cell thymoma with marked granulomatous reaction: report of a case with review of literature. Int J Surg Pathol. 2003;11:353-6.

4. Ray JG, Shmorgun D, Chan WS. Common C677T polymorphism of the methylenetetrahydrofolate reductase gene and the risk of venous thromboembolism: meta-analysis of 31 studies. Pathophysiol Haemost Thromb. 2002;32:51-8.

5. Thurmon TF. Folic acid: miscarriages, anomalies, thromboses, cancers. J La State Med Soc. 2001;153:98-103.

\title{
Anterior transclavicular approach to malignant tumors of the thoracic inlet: Importance of the scapulothoracic articulation
}

\author{
Marc de Perrot, MD, a and Raja Rampersaud, MD, ${ }^{\mathrm{b}}$ Toronto, Canada
}

T he anterior transclavicular approach for lung cancer invading the thoracic inlet was described by Dartevelle and colleagues. ${ }^{1}$ Although this approach provides excellent exposure to the thoracic inlet, it has often been criticized because of potential deformity and dysfunction of the shoulder related to resection of the clavicle. However, the proximal part of the clavicle plays a minor role in the stability and function of the shoulder as long as the integrity of the scapulothoracic articulation is preserved. ${ }^{2,3}$ The scapulothoracic articulation is formed by the attachment of the scapula to the chest wall through the trapezius, latissimus dorsi, rhomboid, levator scapulae, and serratus anterior muscles. ${ }^{4,5}$ Thus, preservation of these muscles and their nerves is crucial to achieve good functional and cosmetic results. We emphasize the importance of preserving the spinal accessory, dorsal scapular, and long thoracic nerves that are running in the posterior cervical triangle and innervate the trapezius, rhomboid, and serratus anterior muscles, and we document the good functional and cosmetic results obtained with this approach despite resection of the clavicle if the scapulothoracic articulation is preserved.

From the Divisions of Thoracic Surgery a and Orthopaedic Surgery, ${ }^{\mathrm{b}}$ Toronto General Hospital and Toronto Western Hospital, University of Toronto, Canada.

Received for publication April 16, 2007; accepted for publication May 14, 2007.

Address for reprints: Marc de Perrot, MD, MSc, Division of Thoracic Surgery, Toronto General Hospital, 9N-961, 200 Elizabeth Street, Toronto, Ontario M5G 2C4, Canada (E-mail: marc.deperrot@uhn.on.ca).

J Thorac Cardiovasc Surg 2007;134:801-3

$0022-5223 / \$ 32.00$

Copyright $\odot 2007$ by The American Association for Thoracic Surgery

doi:10.1016/j.jtcvs.2007.05.022

\section{Clinical Summary}

The anterior transclavicular approach has been described in detail, ${ }^{1}$ and we will therefore limit our description to some specific points only. An incision is made along the sternocleidomastoid muscle and extended horizontally along the third rib. The extension of the incision ranges from the level of the jaw down to the third rib to permit optimal exposure of the thoracic inlet and pulmonary hilum. The sternocleidomastoid and pectoralis major muscles are dissected off the chest wall and elevated together with the skin as a myocutaneous flap. The preservation of a myocutaneous flap is important to obtain adequate healing of the wound. The clavicle is freed up to the point where the subclavian vein crosses behind the clavicle.

The spinal accessory nerve should be identified in the upper part of the cervical incision at the posterior edge of the sternocleidomastoid muscle lateral to the internal jugular vein. The nerve then runs in the posterior cervical triangle in front of the levator scapulae and trapezius muscles, which form the lateroposterior border of the surgical field behind the elevated myocutaneous flap (Figure 1).

Division of the scalenus anterior muscle will expose the brachial plexus and the subclavian artery. At this point, branches of the fifth (C5), sixth (C6), and seventh (C7) cervical nerve roots passing through the body of the scalenus medius muscle can be identified emerging on the lateral aspect of this muscle just above the brachial plexus (Figure 1). These small branches (1-2 mm) must be preserved when the scalenus medius muscle is divided from the first rib because they will form the dorsal scapular (branches of C5) and long thoracic nerves (branches of C5, C6, and $\mathrm{C} 7$ ) innervating the rhomboid and serratus anterior muscles, respectively.

Division of the first and second rib at the costosternal junction and the third rib along the posterior axillary line provides excellent exposure to the pulmonary hilum to perform the upper lobectomy and mediastinal lymph node dissection (Figure 1). If involved by 